\title{
DIRETIVAS ANTECIPADAS DE VONTADE NO BRASIL: ASPECTOS RELEVANTES SOBRE A VALIDADE E A EFETIVIDADE
}

\author{
ADVANCE HEALTHCARE DIRECTIVES IN BRAZIL: RELEVANT ASPECTS \\ ON VALIDITY AND EFFECTIVENESS
}

Filipe José Medon Affonso ${ }^{1}$

"Não tenho medo da morte
Mas sim medo de morrer
Qual seria a diferença
Você há de perguntar
É que a morte já é depois
Que eu deixar de respirar
Morrer ainda é aqui
Na vida, no sol, no ar
Ainda pode haver dor
Ou vontade de mijar".

(Não Tenho Medo da Morte - Gilberto Gil)

\begin{abstract}
RESUMO
O presente artigo cuida das Diretivas Antecipadas de Vontade (DAV), que são uma realidade no Brasil, apesar da omissão legislativa, que vem causando diversos questionamentos quanto à validade e à efetividade de certos arranjos. As DAVs expressam a autonomia existencial dos indivíduos, consagrando a liberdade no âmbito das escolhas quanto à terminalidade da vida. No aspecto da efetividade, há alguns obstáculos práticos a serem enfrentados, como a ausência de um registro nacional e a dificuldade de acesso dos médicos ao conteúdo das diretivas. Quanto à validade, surgem alguns questionamentos em relação à viabilidade de certas disposições, como é o caso da possibilidade (i) de o procurador para fins de saúde aceitar seu munus apenas quando tomar conhecimento das DAVs; (ii) da instituição de uma junta de procuradores que tomasse as decisões relativas à terminalidade da vida com base em deliberações que atendessem a critérios previstos nas DAVs. Além disso, seria possível haver um mandato duradouro através do qual o declarante delegasse as decisões finais inteiramente a uma pessoa, sem que manifestasse seus desejos através de um testamento vital? Pode o declarante não indicar uma pessoa específica, mas alguém a ser especificado? Ou tais disposições desnaturam o instituo tal como este foi forjado? O objetivo da presente análise é, portanto, analisar estes arranjos, à luz da autonomia existencial, atentando-se sempre para a dignidade da pessoa humana como vetor.
\end{abstract}

Palavras-chave: autonomia existencial; terminalidade da vida; biodireito

\begin{abstract}
This article deals with the Advance Healthcare Directives, which are a reality in Brazil, despite the legislative omission, which has been arising several questions regarding the validity and effectiveness of certain arrangements. The AHDs express the existential autonomy of individuals, consecrating freedom in the context of choices regarding the terminality of life. In terms of effectiveness, there are some practical obstacles to be faced,

1 Mestrando em Direito Civil pela Universidade do Estado do Rio de Janeiro (UERJ). Graduado pela mesma instituição. Advogado.
\end{abstract}


such as the absence of a national registry and the difficulty for doctors to access the content of directives. As to the validity, some questions arise regarding the feasibility of certain provisions, such as the possibility (i) of the healthcare proxy agent to accept his munus only when he becomes aware of the AHDs; (ii) the establishment of a board of healthcare proxy agents to make decisions regarding the termination of life based on deliberations that meet the criteria previously established in the AHDs. Moreover, could there be a healthcare proxy whereby the declarant delegates the final decisions entirely to a person without expressing his wishes through a living will? Can the declarant not indicate a specific person, but someone to be specified? Or do such provisions denature the institution as it was forged? The objective of the present analysis is, therefore, to analyze these arrangements, in light of the existential autonomy, always taking into consideration the human person's dignity as a vector.

Keywords: existential autonomy; terminality of life; biolaw

\section{INTRODUÇÃO}

Desde a sua origem, o Direito Civil clássico, de cunho eminentemente patrimonial, se ocupa do fenômeno da morte. Afinal, era preciso dar um destino ao acervo patrimonial do de cujus, respondendo a duas questões principais: quem herda e em qual proporção?

Mas os tempos são outros. A mudança de valores na sociedade refletiu no Direito. Operacionalizando tal transformação no Brasil, a Constituição de 1988 levou à consecução uma verdadeira releitura do Direito Civil, que, ancorado na tábua axiológica da Carta, passou a ser guiado pelo primado das situações existenciais sobre as situações patrimoniais. ${ }^{2}$

Essa mudança de valores também impactou o tema da morte. Hoje, tão importante quanto discutir o que se fazer com o patrimônio de quem morre, é assegurar que se morra de uma forma digna. Fala-se, até mesmo, num direito à morte digna, isto é, que os derradeiros momentos de vida de uma pessoa devem ser como todos os que o antecederam: igualmente dignos. $^{3}$

É aí que entram em cena as denominadas Diretivas Antecipadas de Vontade (DAV's) ${ }^{4}$, as quais surgiram na prática costumeira e, a cada dia mais, vêm sendo incorporadas ao debate legislativo, gerando discussões sobre a produção normativa a respeito do tema.

2 TEPEDINO, Gustavo. Marchas e contramarchas da constitucionalização do Direito Civil: a interpretação do direito privado à luz da Constituição da República. [Syn]Thesis, Rio de Janeiro, vol.5, nº 1, 2012, pp. 15-21, p. 16

3 BARROSO, Luís Roberto; MARTEL, Letícia de Campos Velho. A morte como ela é: dignidade e autonomia individual no final da vida. Os Constitucionalistas. Disponível em: <http://osconstitucionalistas.com.br/Artigos/A_Morte_Como_Ela_E-Barroso_Martel.pdf> Acesso em 03 fev. 2019

4 Necessário fazer desde já uma distinção terminológica, essencial para o prosseguimento da análise. Nesse sentido, Amanda Cordeiro de Souza define que: "As diretivas antecipadas de vontade constituem gênero que abrange as espécies de testamento vital e mandato duradouro. A primeira é mais conhecida e serve a determinar a quais tratamentos uma pessoa deseja ser submetida, a fim de estender artificialmente sua vida, quando não mais gozar de capacidade e estiver em situação de terminalidade. A segunda, foco deste trabalho, consiste na indicação de terceira pessoa para tomar este tipo de decisão em substituição àquele que perdeu, ainda que temporariamente, o discernimento para tanto (...)". In: SOUZA, Amanda Cordeiro de. Diretivas antecipadas de vontade: dignidade e autonomia. Revista de Direito de Família e das Sucessões (RDFAS), 
Neste sentido, "as diretivas antecipadas de vontade têm a função de dar ao paciente o poder de recusar tratamentos e, também, de escolher, dentre aqueles possíveis, o tratamento que lhe convém, o que significa que estamos diante do exercício da autonomia privada do paciente." 5

O medo refletido na canção do compositor baiano Gilberto Gil é justamente o que se tenta amenizar com essas diretivas. Não se trata mais de pensar no acervo patrimonial do indivíduo, mas em como impedir ou minimizar a dor sofrida nos momentos que antecedem a morte. E, para a pessoa humana, a importância dessa etapa é até mesmo maior que a etapa seguinte, pois, como diz a canção, morrer ainda é aqui, quando pode haver dor. Já a morte é quando se deixa de respirar. Assim, para a morte, testamento. Para o morrer, diretivas. ${ }^{6}$

Todavia, embora as Diretivas Antecipadas de Vontade sejam uma expressão da autonomia privada do indivíduo ${ }^{7}$, problemas de efetividade fazem com que esta autonomia não seja respeitada. É aqui que se encontram e se conjugam as duas palavras que serão o norte deste breve estudo: validade e efetividade. Explica-se.

A falta de critérios, sobretudo normativos, para se aferir a extensão da validade das diretivas, conjugado com a ausência de regulação sobre a matéria são alguns dos fatores que levam a uma falta de efetividade do instituto no Brasil. Num sentido metafórico, é como se fosse um instrumento de cordas desafinado, isto é, não se questiona muito que o instituto exista, nem que possa produzir boa música, mas, tal como se apresenta hoje, ele carece de efetividade, porque está desafinado e demanda uma atuação conjugada de diversos atores para

coord. Carlos Alberto Garbi, Regina Beatriz Tavares da Silva e Theodureto de Almeida Camargo Neto. São Paulo: Associação de Direito de Família e das Sucessões, jul/set. 2017, v. 13, p. 23.

5 SÁ, Maria de Fátima Freire de; MOUREIRA, Diogo Luna. Autonomia para morrer: eutanásia, suicídio assistido, diretivas antecipadas de vontade e cuidados paliativos, 2. ed. Belo Horizonte: Del Rey, 2015, pp. 176-177

6 "José de Oliveira Ascensão é enfático ao negar às disposições antecipadas de vontade (e não diretivas, conforme prefere o autor) a natureza de um testamento, dado que este "encerra a última vontade, no sentido de vontade expressa para ter eficácia depois da morte", ao passo em que o "chamado testamento vital só poderá ter eficácia em vida". A assimilação do testamento vital ao testamento implicaria também a necessidade de se exigir de seu autor a capacidade testamentária ativa, que é bem diversa da capacidade civil genérica, esta última única exigida para as diretivas antecipadas de vontade" (RODRIGUES JUNIOR, Otavio Luiz. Diretivas antecipadas de vontade: questões jurídicas sobre seu conceito, objeto, fundamento e formalização, pp. 381-392. In: SILVEIRA, Renato de Mello Jorge; GOMES, Mariângela Gama de Magalhães. (organizadores). Estudos em homenagem a IvetteSenise Ferreira. São Paulo: LiberArs, 2015, p. 383)

7 "O termo "autonomia" significa, de um modo geral, "independência, ausência de imposições ou coações externas", ou seja, está a ser autónomo aquele que toma decisões por si, baseadas no conhecimento e na compreensão da situação, sem a coerção de terceiros. No âmbito das DAV, em particular, a autonomia do doente prende-se sobretudo com "a ausência de limitações e incapacidades pessoais que impeçam ou diminuam a liberdade de decisão", ou seja, depende da existência de competência por parte do doente." BANDEIRA, M. Diretivas antecipadas de vontade: muitas questões e ainda mais respostas. Faculdade de Medicina, Universidade de Coimbra, Portugal. Disponível em: <https://estudogeral.sib.uc.pt/bitstream/10316/37296/1/Diretivas\%20antecipadas\%20de\%20vontade\%20muit as\%20questoes\%20e\%20ainda\%20mais\%20respostas.pdf> Acesso em 03 fev. 2019, pp. 7-8 
operar satisfatoriamente. Assim, necessário se faz que a doutrina lance as bases sólidas para a concepção do instituto, que a jurisprudência continue o acolhendo, cada vez de forma mais ampla, que o Poder Legislativo regule aspectos relevantes e, por fim, que a sociedade, sobretudo o segmento médico, adira a esta prática, naturalizando-a para os pacientes, a fim de que se crie uma cultura de Diretivas Antecipadas de Vontade no Brasil.

Bem consolidada, tal cultura impediria ou, pelo menos, reduziria grande parte das questões que surgem quando uma pessoa humana está inconsciente sobre um leito de hospital e é preciso tomar decisões quanto ao prolongamento ou não de sua vida e sobre o modo de fazê-lo.

Dúvidas não há, todavia, que seja qual for a orientação adotada, isto é, quer se opte pela regulação legislativa, quer se estimule a ausência de regulação, é preciso considerar que a valorização das situações existenciais ante as patrimoniais faz com que se demande maior atenção para o momento que antecede a morte, enquanto expressão da dignidade humana.

Com base nisso, este artigo se propõe a analisar questões pontuais quanto à validade e à efetividade das Diretivas Antecipadas de Vontade, como: prazo de validade e revogabilidade, conflito entre os desejos da família e do declarante, a falta de um Registro Nacional, dentre outras.

\section{REQUISITOS DE VALIDADE}

\subsection{REGULAÇÃO NO BRASIL}

A Resolução $\mathrm{n}^{\circ}$. 1.995/2012 do Conselho Federal de Medicina $^{8}$ foi a primeira regulamentação sobre o tema no Brasil. Embora se reconheça a sua inegável importância de ter dado um ponto de partida para a discussão normativa do tema, é preciso lembrar que as resoluções do CFM não possuem caráter jurídico, isto é, são normas deontológicas, que se destinam, de um modo geral, à comunidade médica. Além disso, a Resolução em questão, de apenas três artigos, deixou de se ocupar de importantes questões, o que faz crescer a necessidade de se legislar mais sobre o tema. ${ }^{9}$

8 DADALTO, Luciana. Reflexos jurídicos da Resolução CFM 1.995/12. Revbioét (Impr.) 2013; 21 (1): $106-$ 12, pp. 108-109

9 Neste mesmo sentido, Luciana Dadalto arremata: "É preciso, entretanto, ter em mente que a resolução não esgota o tema, pelo contrário, demonstra a necessidade de legislação específica sobre as diretivas antecipadas de vontade a fim de regulamentar questões afetas ao discernimento do outorgante, a uma exemplificação de cuidados e tratamentos que podem ou não ser recusados, bem como quais são os critérios para aceitação e 
Importante destacar, todavia, que a própria Exposição de Motivos da Resolução traz o dado de que "pesquisas internacionais apontam que aproximadamente 90\% dos médicos atenderiam às vontades antecipadas do paciente no momento em que este se encontre incapaz para participar da decisão (Simón-Lorda, 2008; Marco e Shears, 2006)" ${ }^{10}$ Isso denota a relevância do instituto, que, segundo tal pesquisa, ajudaria a concretizar a vontade dos pacientes nos momentos em que estes não mais pudessem exprimir suas vontades.

Ademais, em diversos momentos, a Resolução afirma que o médico levará em consideração as diretivas do paciente, prevalecendo estas até mesmo sobre os desejos dos familiares, salvo se elas estiverem em desacordo com os preceitos ditados pelo Código de Ética Médica.

Além desta Resolução, destaca-se também o Enunciado nº 37 da I Jornada de Direito da Saúde do Conselho Nacional de Justiça:

As diretivas ou declarações antecipadas de vontade, que especificam os tratamentos
médicos aos quais o declarante deseja ou não se submeter quando incapacitado de
expressar-se autonomamente, devem ser feitas preferencialmente por escrito, por
instrumento particular, com duas testemunhas, ou público, sem prejuízo de outras
formas inequívocas de manifestação admitidas em direito.

Tal redação não passa livre de críticas. Nesse mister, Luciana Dadalto ${ }^{11}$ aponta que o Enunciado restringiu as diretivas a tratamentos médicos, sendo que elas também poderiam envolver cuidados e até disposições sobre enterros. Além disso, a redação não menciona a figura do procurador e equipara o instituto a um negócio jurídico, quando, na verdade, as DAV's deveriam ser vistas como uma declaração unilateral de vontade, segundo Dadalto.

Não parece haver grande prejuízo, todavia, uma vez que o Enunciado não goza de força normativa, razão pela qual a doutrina e a jurisprudência podem tanto ampliar quanto reduzir o seu alcance. Ele serve, apenas, como um reforço argumentativo para se atestar que as diretivas são plenamente válidas no Brasil.

A conclusão parcial a que se chega é que é preciso legislar sobre o tema. A insuficiência de instrumentos normativos sobre as diretivas é um dos fatores que conduz à sua falta de efetividade prática. Tantas dúvidas sobre o instituto levam a uma insegurança crescente. A primeira delas diz respeito aos aspectos registrais.

\subsection{A OBRIGATORIEDADE DO REGISTRO EM CARTÓRIO DE NOTAS}

recusa dos mesmos ao registro das diretivas antecipadas, e à extensão da participação do médico na feitura das diretivas." (DADALTO, Luciana. Testamento Vital, 3. ed. São Paulo: Atlas, 2015, p. 173)

10 Resolução disponível em: <http://www.portalmedico.org.br/resolucoes/cfm/2012/1995_2012.pdf>

11 DADALTO, Luciana. Testamento Vital, 3. ed. São Paulo: Atlas, 2015, p. 176-178 
No estado da arte atual da legislação brasileira, não há obrigatoriedade de se levar as diretivas a registro em cartório. Trata-se, portanto, de mera faculdade conferida ao declarante, que, ao optar pelo registro, confere publicidade e, em tese, maior segurança ao documento, eis que lavrado diante de um oficial de registros com fé pública.

É de se questionar, no entanto, a utilidade de um registro. E a experiência de outros países parece ser um caminho interessante para se analisar este aspecto. Na Espanha, por exemplo, "a lei que instituiu o testamento vital criou um Registro Nacional de Instruções Prévias subordinado ao Ministério da Sanidad y Consumo, registro este totalmente informatizado." ${ }^{\prime 2}$ Neste país, o registro pode ser feito tanto por escritura pública, como por escritura particular, com testemunhas, embora não haja previsão do número necessário de testemunhas. ${ }^{13}$

Por outro lado, no caso dos Estados Unidos da América, pioneiros na adoção das diretivas, não há "qualquer exigência quanto à forma, se pública ou privada, mesmo porque se afirma não haver, naquele país, cartórios notariais como os existentes no Brasil."14

Não obstante, alguns estados norte-americanos exigem que o documento seja firmado e assinado por duas testemunhas ou, como ocorre no estado da Geórgia, por três testemunhas se for assinado no hospital, devendo a terceira ser o chefe do corpo médico ou um médico que não tenha participado do tratamento. Lá também há algumas restrições quanto a quem pode servir como testemunha. Assim, se evita como testemunha, por exemplo, pessoas com parentesco, beneficiários do testamento patrimonial, responsáveis financeiramente pelo tratamento, dentre outros. ${ }^{15}$

A conclusão a que se chega é que hoje, no Brasil, o registro não é obrigatório, diante da ausência de legislação expressa nesse sentido. Como se verá mais a frente, a falta de um registro nacional das diretivas é um dos maiores óbices à sua efetividade. Desse modo, se pode argumentar que um registro nacional, com amplo acesso pelos serviços hospitalares, seria um importante mecanismo para garantir que a vontade do declarante seja implementada. Não obstante, permanece a questão: seria o registro obrigatório ou bastaria um instrumento particular? Neste momento, a opção é aguardar o legislador.

12 DADALTO, Luciana. Testamento Vital, 3. ed. São Paulo: Atlas, 2015, p. 184

13 DADALTO, Luciana. Testamento Vital, 3. ed. São Paulo: Atlas, 2015, p. 184

14 PONA, Éverton Willian. Testamento vital e autonomia privada. Curitiba: Juruá, 2015, p. 101

15 PONA, Éverton Willian. Testamento vital e autonomia privada. Curitiba: Juruá, 2015, p. 101 
Mas enquanto a legislação não vem, a doutrina tem tentado criar parâmetros quanto à forma das diretivas. Um deles seria a impossibilidade de se incluir as diretivas em outros documentos. É o que defende Luciana Dadalto, para quem:

As DAV não podem ser incluídas em escrituras públicas de testamento público, constituição de união estável ou qualquer outro documento, pois referem-se a relações jurídicas sui generis, que envolvem questões éticas da relação médicopaciente. Ademais, possuem requisitos e especificidades próprias, que não podem ser confundidas com a de outros institutos. ${ }^{16}$

Essas são, contudo, apenas sugestões doutrinárias, e, ante o silêncio do legislador, não há, em princípio, óbice legal a que as diretivas sejam apostas em outros documentos, embora seja recomendável que o documento seja autônomo, dadas as suas especificidades.

\subsection{NECESSIDADE DE ACEITAÇÃO POR PARTE DO PROCURADOR PARA CUIDADOS $D E S A U ́ D E$}

A figura do procurador para cuidados (ou fins) de saúde gera questionamentos de diversas ordens. A começar pela sua natureza jurídica: seria ele um mandatário? Deveria ele atuar segundo a vontade presumida do declarante? Esses são alguns aspectos a serem esclarecidos. ${ }^{17}$ Por ora, basta pontuar que o procurador para cuidados de saúde é aquela pessoa indicada pelo declarante, a quem poderá caber tanto efetivar e fiscalizar o cumprimento das disposições, como, em alguns casos, decidir pelo declarante segundo sua vontade. Trata-se do instituto da procuração para cuidados de saúde ou mandato duradouro. ${ }^{18}$

Acerca deste procurador, discute-se se seria necessário que ele aceitasse a sua nomeação no momento da confecção do documento ou se poderia emitir sua aceitação mais tarde, quando fosse chamado para exercer seu munus.

No Direito Comparado, vê-se o caso da França, por exemplo, onde "a nomeação de representante para fins de saúde exige que a pessoa nomeada esteja ciente das escolhas do

16 DADALTO, Luciana. Aspectos registrais das diretivas antecipadas de vontade. Civilistica.com, a. 2. n. 4. 2013, p. 7

17 GONZÁLES, José Alberto. Testamento Vital e Procuração de Cuidados de Saúde. Lisboa: Quid Juris, 2013, pp. 139-146

18 A doutrina diverge quanto à nomenclatura mais correta. No Brasil, tem-se adotado a nomenclatura "mandato duradouro", embora esta não expresse a totalidade do sentido contido na expressão original do direito norteamericano, de onde adveio: "durablepowerofattorney for healthcare". "Em verdade, mandato duradouro corresponderia, no máximo, à tradução de durablepowerofattorney." (PONA, Éverton Willian. Testamento vital e autonomia privada. Curitiba: Juruá, 2015, p. 49) Para os fins deste trabalho, contudo, adotar-se-ão ambas as expressões de forma indistinta. 
paciente, de forma que a lei autoriza que a pessoa nomeada possa acompanhá-lo em seus esforços e participar de consultas médicas para apoiar suas decisões." 19

Segundo o Código da Saúde Pública francês,

Toute personne majeure peut désigner une personne de confiance qui peut être un parent, un proche ou le médicin traitant, et qui sera consultée au cas où elle-même serait hors d'état d'exprimer sa volonté et de recevoir l'information nécessaire à cette fin. Cette désignation est faite par écrit. Elle est révocable à tout moment. Si le malade le souhaite, la personne de confiance l'accompagne dans sés démarches et assiste aux entretiens médicaux afin de l'aider dans ses décisions. (art. L1111-6, Code de la Santé Publique)20

Para os franceses, então, o declarante designa por escrito um procurador, que, sendo uma das pessoas indicadas pela lei, poderia lhe acompanhar durante os procedimentos médicos para lhe assistir na tomada de decisões, bem como decidir por ele caso o declarante não possa exprimir sua vontade ou receber a informação necessária para esse fim.

A preocupação do legislador francês é que a pessoa indicada esteja o mais próximo possível do declarante, com vistas a que, além de lhe auxiliar, possa conhecer de forma mais íntima a vontade que o paciente declarou no documento.

No caso brasileiro, como não há qualquer norma sobre o tema, não há proibições. Eis que surgem algumas perguntas: seria necessário que o procurador eleito também assinasse o documento? Seria possível que ele não tivesse conhecimento das diretivas e só viesse a saber delas quando fosse chamado ao hospital para decidir pelo paciente? Em suma, é necessária a sua aceitação e que ele integre o documento?

Para responder a esta indagação, necessário analisar a finalidade de se indicar um procurador. E isso passa pela palavra "confiança". O desejo do declarante, ao designar um procurador, é ter alguém, de sua confiança, para dar fiel cumprimento ao disposto nas diretivas. E, como consequência lógica, é necessária a aceitação deste encargo (palavra empregada fora do seu sentido técnico).

O declarante indica, mas o procurador precisa aceitar. Assim, que diferença haveria em aceitar na feitura do documento ou aceitar depois? Unicamente trazer maior confiança ao declarante, que sabe que a pessoa de sua confiança aceitou a missão que lhe foi conferida.

19 SÁ, Maria de Fátima Freire de; MOUREIRA, Diogo Luna. Autonomia para morrer: eutanásia, suicídio assistido, diretivas antecipadas de vontade e cuidados paliativos, 2. ed. Belo Horizonte: Del Rey, 2015, p. 183

20 Tradução livre: “Toda pessoa maior pode nomear uma pessoa de confiança, que pode ser um dos pais, um parente ou o médico do tratamento, e que será consultada caso ela mesma não seja capaz de exprimir sua vontade e receber as informações necessárias para esse fim. Esta designação é feita por escrito. É revogável a qualquer momento. Se o paciente assim desejar, a pessoa de confiança o acompanha em seus procedimentos e participa das consultas médicas a fim de ajudá-lo em suas decisões." 
Todavia, mister pontuar: trata-se do exercício da autonomia da vontade do declarante, que pode ou não designar um procurador.

Logo, parece não haver qualquer óbice a que a aceitação seja tardia, desde que o declarante esteja ciente de que a pessoa indicada possa não vir a aceitar sua designação, embora seja necessário refletir se isso acaba por desnaturar o instituto do da procuração para fins de saúde tal como esta foi concebida.

É de se questionar, ainda, se haveria responsabilidade civil pelo descumprimento, por parte do procurador, do conteúdo das diretivas. Esta, contudo, é uma questão mais sensível, que foge ao escopo desta análise. Permanece, porém, a dúvida: haveria responsabilidade civil, caso, por exemplo, o paciente/declarante não morresse e ficasse com uma sequela devido a um descumprimento por parte do procurador?

\subsection{POSSIBILIDADE DE ELEIÇÃO DE UMA JUNTA DE PROCURADORES}

Usualmente, a doutrina fala na possibilidade de se eleger procuradores substitutos sucessivos $^{21}$, isto é: caso um não esteja presente ou não possa, por qualquer outro motivo, exercer sua função, chama-se o indicado sucessivo. Quanto a isso, parece não haver qualquer dúvida.

Questiona-se, todavia, a possibilidade de se eleger uma junta de procuradores, ou seja, que o declarante designe, por exemplo, três pessoas que, por unanimidade ou por maioria, tomem as decisões indicadas no termo das diretivas.

Um exemplo torna a hipótese mais clara. Assim, se imagina que o paciente designe um familiar, um ministro religioso e um médico, todos de sua confiança. E, no termo das diretivas, estabelece que os três deverão tomar em conjunto, por maioria, as decisões apontadas.

E, caso algum desses falte ou não esteja presente, pode o declarante estabelecer, por exemplo, que se nomeie outra pessoa em substituição ou que apenas um dos que sobraram tome as decisões. São inúmeros os arranjos possíveis.

Será que a tomada de decisões de forma coletiva, como se supõe, seria viável juridicamente? Para se obter essa resposta, não se pode afastar da premissa norteadora das diretivas: estas são uma expressão genuína e pura da autonomia existencial do paciente.

21 DADALTO, Luciana. Testamento Vital, 3. ed. São Paulo: Atlas, 2015, p. 200 
Dessa maneira, tendo a autonomia do paciente como base, a designação da tomada coletiva de decisões parece ser, pelo menos, juridicamente possível. Explica-se: se o paciente não indicar nenhum procurador, será a família ou, na falta dessa, os médicos que tomarão decisões em casos de terminalidade de sua vida. Serão, pois, pessoas não apontadas pelo paciente/declarante.

Quando este designa algumas pessoas, ainda que para tomar decisões coletivas, está fazendo mais do que designar uma junta decisória: está afastando, por exemplo, que seus familiares tomem decisões por ele. E isso é comum, tendo em vista que muitos pacientes fazem diretivas com mandatos duradouros justamente para impedir que familiares desliguem os aparelhos médicos para abreviar a vida do paciente e herdar seu patrimônio mais rapidamente.

Nessa ordem de ideias, não há, ao menos em tese, qualquer óbice a que se eleja uma junta de procuradores. Cabe, contudo, avaliar se esse modo de tomada de decisão seria eficiente na aplicação prática do instituto, uma vez que, quanto mais pessoas se indica, maior a chance de uma delas não estar presente ou impossibilitada de decidir. Todavia, esta é uma questão de aplicação prática e não de direito.

\subsection{NECESSIDADE DA PARTICIPAÇÃO DE UM MÉDICO QUE ORIENTE O DECLARANTE QUANTO À FEITURA DO DOCUMENTO}

No caso português, a legislação foi expressa ao dispor no item 2 do artigo $3^{\circ}$ da Lei 25/2012 de 16 de julho, que "No caso de o outorgante recorrer à colaboração de um médico para a elaboração das diretivas antecipadas de vontade, a identificação e a assinatura do médico podem constar no documento, se for essa a opção do outorgante e do médico." ${ }^{22}$ Com efeito, em terras lusitanas, a participação de um médico que oriente o declarante na elaboração das diretivas consiste em mera faculdade.

Mais uma vez, como não há legislação específica sobre isso, no Brasil não há obrigatoriedade de que um médico oriente o declarante. Todavia, não se pode questionar que a presença de um médico é essencial, uma vez que a maior parte das pessoas não possui conhecimento médico profundo acerca dos tipos de tratamento a que deseja ou não ser submetida, caso esteja em situação de terminalidade.

22 http://www.pgdlisboa.pt/leis/lei_mostra_articulado.php?nid=1765\&tabela=leis 
Por isso, a presença de um médico se mostra muito importante para que o paciente/declarante decida de maneira esclarecida. Não é outra a conclusão de Luciana Dadalto, para quem é “imprescindível a orientação do médico da família do declarante para a realização das diretivas antecipadas, e é exatamente isso que garante que o paciente vai manifestar exatamente sua vontade no documento, afinal, paciente autônomo é aquele bem informado/esclarecido." 23

O que se visa a garantir, dessa maneira, é que o declarante tenha maior liberdade na sua decisão, uma vez que contará com o auxílio de profissionais de saúde capacitados para lhe esclarecer os tipos de tratamento a que pode ser submetido. É um conhecimento que emancipa o paciente, garantindo-lhe uma autonomia decisória verdadeiramente ampla. ${ }^{24}$

Outrossim, a presença de um médico na feitura do documento confere maior robustez ao conteúdo das declarações, na medida em que evita ou minora, por exemplo, as chances de que mais tarde alguém consiga impugnar o seu conteúdo, alegando que o declarante não possuía higidez mental suficiente quando fez o documento. A presença do médico poderia, assim, garantir que o paciente/declarante estava em pleno gozo de suas faculdades mentais quando declarou suas diretivas.

\subsection{CONFLITO ENTRE OS DESEJOS DA FAMÍLIA E DO DECLARANTE}

Tendo ciência do conteúdo das diretivas, poderia a família obrigar os médicos a tomarem decisões distintas daquelas escolhidas pelo declarante?

Nesse sentido, ao tratar de membros da família que não tenham sido eleitos como procuradores, afirma José de Oliveira Ascensão que:

Há todo o interesse em que seriam ouvidos pela equipa médica. Eles poderão trazer esclarecimentos úteis sobre a situação e entendimentos do familiar, e tanto mais quanto mais convivessem com ele. Pode por exemplo ter muito interesse ouvir um filho, mesmo que ainda seja juridicamente incapaz. Neste sentido, são sempre um elemento de diálogo, na prática em situação muito semelhante à do procurador de cuidados de saúde que não seja familiar. Mas, em todos os casos, quer os familiares quer o procurador de cuidados de saúde informam, esclarecem, dialogam - mas não determinam. A responsabilidade final, como dissemos, recai sempre sobre o médico, ou a equipa de cuidados de saúde. 25

23 DADALTO, Luciana. Testamento Vital, 3. ed. São Paulo: Atlas, 2015, p. 166

24 "O consentimento informado é dado especialmente com o tempo, e pode ser retirado com o tempo. Concordamos em que é essencial que se entenda o consentimento informado como um processo que ocorre com o tempo, e que se evite a visão comum de que um formulário de consentimento assinado é a essência do consentimento informado." (BEAUCHAMP, Tom L.; CHILDRESS, James F. Princípios de ética biomédica. Tradução de Luciana Pudenzi. São Paulo: Loyola, 2002, p. 163)

25 ASCENSÃO, José de Oliveira. As disposições antecipadas de vontade - o chamado "testamento vital". Rev. Fac. Direito UFMG, Belo Horizonte, n. 64, pp. 493-517, jan./jun. 2014, p. 512 
$\mathrm{Na}$ visão do doutrinador português, os familiares podem ser úteis para auxiliar os médicos na interpretação das vontades do paciente/declarante, mas a decisão final será sempre baseada nos desígnios do declarante, em respeito à sua autonomia.

No Brasil, a solução a ser adotada é tendencialmente a mesma, quer isto dizer: a vontade do paciente, enquanto expressão máxima da sua personalidade e da sua autonomia, deve ser respeitada, mesmo que a família possua outros interesses.

O que se questiona, todavia, é o problema da atualidade das diretivas, isto é, o que fazer se as diretivas foram feitas em tempos longínquos e a família, no curso dos anos, ouviu reiteradas vezes do paciente que ele gostaria/não gostaria de ser submetido a um tratamento tal, diferentemente daquilo que dispôs em suas diretivas?

E, se no final da vida, o paciente passou a professar diferente crença religiosa e isto fez com que ele mudasse de opinião quanto ao prolongamento artificial da vida? O que fazer em casos como este?

Em tese, a vontade do paciente é soberana. No entanto, nada impede que as partes interessadas ingressem com uma ação judicial, tentando mostrar, com lastro probatório, ao magistrado que aquele documento não reflete mais a vontade do paciente nos seus últimos momentos de lucidez. O Direito Português segue essa lógica, prevendo que as diretivas não devem ser respeitadas quando, por exemplo, se comprove que o outorgante não desejaria mantê-las. ${ }^{26}$

Esta solução não escapa ao casuísmo, mas é melhor do que simplesmente aplicar as diretivas de maneira cega, até mesmo lesando os interesses últimos do paciente que pode não ter tido tempo ou se lembrado de alterar as diretivas e, tão somente, manifestado informalmente e de maneira privada, tal desejo aos seus familiares e amigos mais próximos.

\subsection{PRAZO DE VALIDADE E REVOGABILIDADE}

26 Lei 25/2012, de 16 de Julho, Portugal

"Artigo 6."

Eficácia do documento

1 - Se constar do RENTEV um documento de diretivas antecipadas de vontade, ou se este for entregue à equipa responsável pela prestação de cuidados de saúde pelo outorgante ou pelo procurador de cuidados de saúde, esta deve respeitar o seu conteúdo, sem prejuízo do disposto na presente lei

2 - As diretivas antecipadas de vontade não devem ser respeitadas quando:

a) Se comprove que o outorgante não desejaria mantê-las;

b) Se verifique evidente desatualização da vontade do outorgante face ao progresso dos meios terapêuticos, entretanto verificado;

c) Não correspondam às circunstâncias de facto que o outorgante previu no momento da sua assinatura."

(http://www.pgdlisboa.pt/leis/lei_mostra_articulado.php?nid=1765\&tabela=leis) 
Fora do Brasil, tem-se defendido a necessidade da fixação de um prazo de validade, por dois fundamentos principais, a saber: (i) que as diretivas são documentos dinâmicos, que não podem ser esquecidos depois de elaborados e (ii) que a Medicina avança muito rapidamente, ou seja, pode ser que uma doença incurável à época da feitura do documento tenha se tornado curável quando da data de sua aplicação. ${ }^{27}$

Luciano Dadalto, contudo, discorda desse entendimento. Segundo ela, a revogabilidade ${ }^{28}$ é da essência do documento; logo, se a pessoa pode revogar a diretiva a qualquer tempo, não faria sentido que fosse fixado um prazo de validade. Já quanto aos avanços da Medicina, entende a autora que isso cai por terra diante dos limites do próprio testamento vital, que são os seguintes: “inaplicabilidade de disposições contrárias ao ordenamento jurídico brasileiro, de disposições contraindicadas para a patologia do paciente e recusa de tratamentos que já tenham sido modificados pela ciência médica". ${ }^{29}$

Com base nesse raciocínio, o conteúdo poderia permanecer intacto e válido, mas sem efeitos, como no caso da evolução da Medicina. Essa seria uma maneira de salvaguardar as diretivas como um todo sem revogá-las, ainda que algumas de suas disposições tenham se tornado sem efeito.

Na França, por exemplo, conforme o art. L1111-11 do Code de la Santé Publique, as:

$$
\begin{aligned}
& \text { diretivas são revogáveis a qualquer momento, limitando-se a sua validade no } \\
& \text { período temporal de três anos, antes da inconsciência da pessoa. Portanto, se o } \\
& \text { documento for datado de até três anos antes da inconsciência do paciente, o médico } \\
& \text { levará em conta sua autonomia antecipada em qualquer decisão de intervenção, } \\
& \text { investigação ou tratamento sobre o assunto.30 }
\end{aligned}
$$

$\mathrm{Na}$ experiência francesa, de forma abreviada, pode-se dizer que as diretivas são válidas se feitas em até três anos antes de quando se precisa recorrer a elas. A revogabilidade é atemporal, mas a validade é limitada, tal como no Direito Português, onde as diretivas são eficazes por um prazo de cinco anos a contar de sua assinatura, embora livremente revogáveis a qualquer tempo. ${ }^{31}$

27 DADALTO, Luciana. Testamento Vital, 3. ed. São Paulo: Atlas, 2015, p. 189

28 DADALTO, Luciana; TUPINAMBÁS, Unai; GRECO, Direceu Bartolomeu. Diretivas antecipadas de vontade: um modelo brasileiro. Rev. bioét. (Impr.). 2013; 21 (3): 463-76, p. 470

29 DADALTO, Luciana. Testamento Vital, 3. ed. São Paulo: Atlas, 2015, p. 190

30 SÁ, Maria de Fátima Freire de; MOUREIRA, Diogo Luna. Autonomia para morrer: eutanásia, suicídio assistido, diretivas antecipadas de vontade e cuidados paliativos, 2. ed. Belo Horizonte: Del Rey, 2015, pp. 182-183

31 Lei 25/2012, de 16 de Julho, Portugal

Artigo 2. ${ }^{\circ}$

Definição e conteúdo do documento

1 - As diretivas antecipadas de vontade, designadamente sob a forma de testamento vital, são o documento unilateral e livremente revogável a qualquer momento pelo próprio, no qual uma pessoa maior de idade e capaz, que não se encontre interdita ou inabilitada por anomalia psíquica, manifesta antecipadamente a sua 
A revogabilidade é, portanto, ínsita à própria noção de diretivas, porque ninguém poderia ser feito escravo das decisões pretéritas sobre a própria vida e os tratamentos médicos a que deseja ser submetido.

Já a validade é mais delicada, havendo controvérsia na doutrina, como evidenciado por Luciana Dadalto. A questão não é das mais simples, como se observa do seguinte exemplo teórico: uma pessoa declara nas DAV's que não gostaria de ser submetida a determinada terapia de ressuscitação, mas, anos após, quando se torna portadora de uma enfermidade, como o Mal de Alzheimer, decide, em um intervalo lúcido, revogar tal disposição, dispondo que aceita ser submetida a tal terapia. O que fazer? Qual das vontades prevalece? São questões que caberão à doutrina e à jurisprudência.

\section{PROBLEMAS À EFETIVIDADE}

\subsection{A FALTA DE UM REGISTRO NACIONAL DE DIRETIVAS ANTECIPADAS NO BRASIL}

Um dos maiores, senão o maior, entrave à efetividade das diretivas antecipadas no Brasil é que, em grande parte dos casos, os médicos sequer sabem que o paciente possui tal documento. As razões para isso são das mais variadas ordens: seja porque o paciente esqueceu

vontade consciente, livre e esclarecida, no que concerne aos cuidados de saúde que deseja receber, ou não deseja receber, no caso de, por qualquer razão, se encontrar incapaz de expressar a sua vontade pessoal e autonomamente. (...)Artigo $7 .^{\circ}$

Prazo de eficácia do documento

1 - O documento de diretivas antecipadas de vontade é eficaz por um prazo de cinco anos a contar da sua assinatura.

2 - O prazo referido no número anterior é sucessivamente renovável mediante declaração de confirmação do disposto no documento de diretivas antecipadas de vontade, de acordo com o disposto no n..$^{\circ} 1$ do artigo $3 .^{\circ}$

3 - O documento de diretivas antecipadas de vontade mantém-se em vigor quando ocorra a incapacidade do outorgante no decurso do prazo referido no . $^{\circ} 1$.

4 - Os serviços de RENTEV devem informar por escrito o outorgante de DAV, e, caso exista, o seu procurador, da data de caducidade do documento, até 60 dias antes de concluído o prazo referido no n. ${ }^{\circ} 1$.

Artigo 8. ${ }^{\circ}$

Modificação ou revogação do documento

1 - O documento de diretivas antecipadas de vontade é revogável ou modificável, no todo ou em parte, em qualquer momento, pelo seu autor.

2 - Sem prejuízo do disposto no.$^{\circ}$, a modificação do documento de diretivas antecipadas de vontade está sujeita à forma prevista no artigo $3 .^{\circ}$

3 - O prazo de eficácia do documento de diretivas antecipadas de vontade é renovado sempre que nele seja introduzida uma modificação.

4 - O outorgante pode, a qualquer momento e através de simples declaração oral ao responsável pela prestação de cuidados de saúde, modificar ou revogar o seu documento de diretivas antecipadas de vontade, devendo esse facto ser inscrito no processo clínico, no RENTEV, quando aí esteja registado, e comunicado ao procurador de cuidados de saúde, quando exista. (http://www.pgdlisboa.pt/leis/lei_mostra_articulado.php?nid=1765\&tabela=leis) 
em casa, seja porque a demora do hospital em localizar o documento não condizia com a rapidez que a intervenção clínica exigia.

Otávio Luiz Rodrigues Junior também se inquieta com essas preocupações:

O paciente elaborou um conjunto de diretivas, as quais devem ser "prévia e expressamente" manifestadas ao médico, devendo sua formulação ter ocorrido de modo livre e autônomo. É de se supor, nesta hipótese, que o paciente informará de modo pessoal ou por intermédio de alguém sobre a existência dessas diretivas. Como elas chegarão ao poder do médico é algo também objeto de suposições: i) entrega pelo paciente ou por portador indicado; ii) solicitação do médico aos familiares; iii) requisição judicial, caso não se encontrem em lugar de acesso livre ao médico, ao procurador do paciente ou a seus familiares.32

Atualmente, diante da ausência de regulação, os declarantes se veem num estado de vulnerabilidade, pois, ou a entrega é feita de maneira física, ou o corpo médico decide, por conta própria, buscar se o paciente possui algum documento escrito junto à família ou mediante requisição judicial.

Uma possível solução para esse problema passa pela criação de um registro nacional, com amplo acesso pelos médicos, que poderiam acessar o banco de dados e consultar se aquele paciente possui ou não algum documento dessa natureza. Para isso, inicialmente, seria necessário criar uma obrigação legal de que, diante de casos de terminalidade da vida dos pacientes, os hospitais consultassem o banco de dados desse registro, sendo civilmente responsáveis pelo descumprimento dessa obrigação.

Tal solução permitiria conferir maior efetividade no cumprimento dos desígnios e vontades do paciente, evitando-se que sua declaração se torne inócua. "Assim, existindo tais disposições formais, o cartório deverá encaminhar as diretivas antecipadas ao Registro Nacional, em um prazo exíguo, a fim de garantir a efetividade" ${ }^{\text {,33 }}$ como aponta Luciana Dadalto.

A sociedade civil já criou no Brasil um modelo de Registro Nacional, o RENTEV (Registro Nacional de Testamento Vital), que em seu sítio eletrônico fornece a seguinte descrição:

A proposta do RENTEV é criar o primeiro - e maior - banco de dados de testamentos vitais no Brasil. Assim, convidamos todos que já tiverem feito seu testamento vital a armazená-lo no nosso sistema, que é totalmente seguro e ainda permite ao usuário entregar um código de acesso a uma pessoa de confiança. Ressaltamos ainda, que o presente arquivo pretende viabilizar a realização de testamentos vitais no Brasil bem como centralizar estes documentos. Todavia, não possui qualquer responsabilidade acerca do cumprimento deste documento pelos

32 (RODRIGUES JUNIOR, Otavio Luiz. Diretivas antecipadas de vontade: questões jurídicas sobre seu conceito, objeto, fundamento e formalização, pp. 381-392. In: SILVEIRA, Renato de Mello Jorge; GOMES, Mariângela Gama de Magalhães. (organizadores). Estudos em homenagem a IvetteSenise Ferreira. São Paulo: LiberArs, 2015, p. 390)

33 DADALTO, Luciana. Testamento Vital, 3. ed. São Paulo: Atlas, 2015, p. 165 
médicos e pela família do paciente, diante da inexistência de legislação específica sobre o assunto no Brasil. Para maior segurança, recomendamos que o testamento vital seja registrado também num Cartório de Notas à escolha do declarante (procedimento ao qual se dá o nome formal de lavratura de escritura pública), a fim de dar publicidade ao ato e resguardar o documento de futuras alegações de nulidade. É provável que algumas pessoas questionem acerca das vantagens de se arquivar o testamento vital neste espaço, principalmente diante da impossibilidade de nos responsabilizar pelo cumprimento. Vejamos: 1. Comprovar a vontade expressa do paciente, pois comumente sabe-se que determinada pessoa gostaria que não the fossem realizados alguns procedimentos mas não consegue-se provar este desejo; 2. Evitar que o testamento vital se perca; 3. Facilitar que a família, amigos e/ou médico tenham acesso ao documento, através de uma chave de acesso própria.34

Diante desses fatos, surgem duas questões principais sobre esse registro nacional que se sugere ser criado: (i) há obrigatoriedade de registro em cartório para que as diretivas sejam válidas e vinculantes ou o registro é mera faculdade do declarante?e (ii) tal registro precisa ser público ou pode ser organizado pela sociedade civil?

Para este último questionamento, trata-se de mera discricionariedade do legislador, que poderá escolher tanto um quanto o outro modelo, desde que seja conferida legitimidade a esses registros não estatais. Não obstante, a admissão de regimes não estatais passa por uma questão subjacente: a obrigatoriedade ou não de um registro para conferir validade às diretivas.

Retoma-se, assim, o primeiro questionamento. E para desvendá-lo, necessário se faz perquirir a função de um registro. Assim, de forma sucinta, pode-se dizer que o registro cumpre uma função primacial de conferir publicidade e segurança jurídica às relações. Registra-se um documento em cartório para, dentre outras coisas, dotar de fé pública aquele texto escrito. E, salvo nas hipóteses legais específicas, o registro é mera faculdade.

No caso das diretivas antecipadas, o registro - se contasse com uma base de dados nacional - teria a inegável função de facilitar o acesso dos médicos, garantindo maior efetividade aos desejos do declarante. Além disso, seria um documento muito mais aceito pelos médicos, pois não se trataria de mera folha de papel que um familiar apresenta ao médico quando o declarante está impossibilitado de se comunicar num leito. Seria, ao contrário, um documento que goza de fé pública, o que aumenta a certeza de sua autenticidade para quem, de fato, vai implementar seu conteúdo (e possivelmente ser responsabilizado civilmente em caso de dano): o corpo médico de um hospital.

$\mathrm{Na}$ experiência portuguesa, por exemplo, o registro é meramente facultativo, como se observa do artigo $16^{\circ}$ da Lei 25/2012 de 16 de Julho:

Registo de testamento vital/procuração no RENTEV

34 Registro Nacional de Testamento Vital - RENTEV: www.rentev.com.br 
1 - O registo no RENTEV tem valor meramente declarativo, sendo as diretivas antecipadas de vontade ou procuração de cuidados de saúde nele não inscritas igualmente eficazes, desde que tenham sido formalizadas de acordo com o disposto na presente lei, designadamente no que concerne à expressão clara e inequívoca da vontade do outorgante. 35

Logo, para o Direito Português, as diretivas são válidas desde que sejam cumpridos os requisitos formais, ainda que elas não tenham sido registradas. Semelhante solução poderia ser adotada no Brasil, eis que criar uma obrigação de registro ao paciente poderia ser um empecilho à efetividade das diretivas. E, em se tratando de direitos existenciais, quanto menos entraves burocráticos à sua concretização, mais bem atendido é o comando da dignidade da pessoa humana.

\subsection{ANULAÇÃO PELA FALTA DE CONSENTIMENTO LIVRE E INFORMADO}

Discute-se no Direito Português se a falta de consentimento livre e informado seria motivo suficiente para a anulação do conteúdo de uma diretiva. A hipótese é simples: no momento em que vai se aplicar a diretiva, alguém alega que o paciente não foi livremente esclarecido quando declarou o conteúdo daquele documento.

Como aponta José Alberto Gonzáles acerca da experiência portuguesa:

Em geral, o consentimento informado serve para excluir a ilicitude de um comportamento que, na sua falta, seria antijurídico. No âmbito do testamento vital ele desempenha, todavia, um papel distinto: como somente mediante o fornecimento de todos os dados relevantes para a formação da vontade do seu autor se pode dizer que este se motivou de modo esclarecido, aquele torna-se pressuposto da sua válida celebração. A respectiva falta funciona, portanto, como fundamento de invalidação do living will.36

Os componentes analíticos do consentimento informado seriam cinco elementos: competência, revelação, entendimento, voluntariedade e consentimento. Tais elementos são, então, apresentados como a matéria-prima para se construir uma definição do que seja um consentimento informado. "Um indivíduo dá um consentimento informado para uma intervenção se (e, talvez, somente se) for capaz de agir, receber uma exposição completa, entender a exposição, agir voluntariamente e consentir na intervenção."37

35 Disponível em: <http://www.pgdlisboa.pt/leis/lei_mostra_articulado.php?nid=1765\&tabela=leis>

36 GONZÁLES, José Alberto. Testamento Vital e Procuração de Cuidados de Saúde. Lisboa: Quid Juris, 2013, p. 108

37 BEAUCHAMP, Tom L.; CHILDRESS, James F. Princípios de ética biomédica. Tradução de Luciana Pudenzi. São Paulo: Loyola, 2002, p. 165 
Por conseguinte, a falta de um consentimento informado é um motivo relevante o suficiente para se invalidar o conteúdo de uma diretiva. O problema em si está na questão probatória: como comprovar a ausência de consentimento informado?

Para isso, a legislação deve garantir, como dito antes, que, por exemplo, um médico participe da confecção da diretiva e a ela subscreva. É claro que isso não elimina completamente os riscos da falta de consentimento, mas, em tese, os minora consideravelmente.

Por essas razões, no plano abstrato é de se considerar que, se comprovada for, a ausência de consentimento livre, esclarecido e informado é um motivo justificador para se anular o conteúdo de uma diretiva.

\subsection{PODE HAVER PROCURAÇÃO PARA CUIDADOS DE SAÚDE SEM TESTAMENTO VITAL?}

De forma resumida, pode-se dizer que uma diretiva pode conter duas partes distintas: uma procuração para cuidados/fins de saúde (mandato duradouro) ${ }^{38}$ e um testamento vital. Este último seria "a declaração antecipada e lúcida de vontade de uma pessoa, sobre o desejo de receber ou não receber tratamento ou proteção a partir do momento, por qualquer motivo, em que torna-se incapaz de manifestar a sua vontade". 39

Já a procuração para cuidados de saúde seria o "documento no qual o paciente nomeia um ou mais 'procuradores' que deverão ser consultados pelos médicos, em caso de incapacidade do paciente - definitiva ou não -, quando estes tiverem que tomar alguma decisão sobre recusa de tratamento". 40

Nesta modalidade, vige a noção de juízo substitutivo, feito pelo responsável, isto é, "significa que o representado deve tomar decisões consoantes com aquela que seria a opção do paciente. Ou seja, o procurador de cuidados de saúde, dever ser um mero transmissor da vontade formulada pelo outorgante."41

38 “(...) entendem-se como mais adequadas as denominações de 'procuração para cuidados de saúde’ para o documento por meio do qual uma terceira pessoa é nomeada; 'procurador para cuidados de saúde' a pessoa nomeada e 'mandato duradouro para cuidados de saúde' para o negócio jurídico instrumentalizado por meio da procuração que viabiliza os poderes de representação". (PONA, Éverton Willian. Testamento vital e autonomia privada. Curitiba: Juruá, 2015, p. 51)

39 FARAH, Elias. Testamento vital. Instituto em discussão. Breves reflexões sobre o tema. Previsão Legislativa. Revista de Direito de Família e das Sucessões, vol. 7, 2016, Jan/Mar, 2016, p. 45

40 DADALTO, Luciana. Testamento Vital, 3. ed. São Paulo: Atlas, 2015, p. 91

41 SOUZA, Amanda Cordeiro de. Diretivas antecipadas de vontade: dignidade e autonomia. In: Revista de Direito de Família e das Sucessões (RDFAS), coord. Carlos Alberto Garbi, Regina Beatriz Tavares da Silva 
Na explicação de Jorge Luis Manzini:

Las decisiones del paciente son subrogadas - tomadas em su nombre - por el apoderado, en base a su conocimiento del paciente y de sus preferencias; es decir, el apoderado no debe indicar lo que mejor le parece a él sino lo que cree que el paciente hubiera elegido para esa circunstancia particular.42

Em síntese, pode-se dizer que, normalmente, o procurador atua com base no conteúdo do testamento vital, o qual expressa as vontades do paciente. É este o documento que serve de parâmetro para se avaliar a atuação do procurador, isto é, para se verificar se ele atuou ou não com base nos desejos do declarante.

A hipótese que se aventa aqui é outra: seria possível que uma pessoa delegasse as decisões sobre terminalidade inteiramente a uma pessoa, sem que manifestasse seus desejos através de um testamento vital?

Um exemplo didático traduz melhor esses questionamentos. Assim, por exemplo, podese imaginar que determinada pessoa idosa, ao receber o diagnóstico inicial de uma doença degenerativa, ainda em estágio primitivo, opte por eleger como procurador um ministro de sua confissão religiosa, a fim de que ele decida com base nas orientações de sua religião, pois a paciente gostaria que as decisões em caso de terminalidade fossem tomadas com base na sua crença religiosa.

Será que nesse caso o mandato estaria desconfigurado, tendo em vista que o procurador não agiria nos limites do testamento vital, mas sim com base na doutrina de uma crença religiosa, por exemplo? Haveria possibilidade de controle, caso, por exemplo, o ministro religioso decidisse de maneira diversa ao que prega a religião da pessoa?

Pode-se ir além. E se o declarante não indica uma pessoa específica, mas alguém a ser especificado? Imagine-se a seguinte cláusula: “como procurador para fins de saúde, desejo que seja escolhido o padre que estiver chefiando a Catedral Metropolitana da cidade do Rio de Janeiro, a fim de que ele tome as decisões por mim caso eu não possa manifestar minha vontade". Seria possível?

Mais uma vez, é preciso retornar à ideia de autonomia. As diretivas são, assim, expressão máxima da ideia de autonomia existencial da pessoa humana, que não deseja, por exemplo, ser submetida a tratamentos infrutíferos e estéreis, que apenas prolongarão sua vida

e Theodureto de Almeida Camargo Neto. São Paulo: Associação de Direito de Família e das Sucessões, jul/set. 2017, v. 13, p. 23

42 Tradução livre: "As decisões do paciente são sub-rogadas - tomadas em seu nome - pelo mandatário, com base no seu conhecimento acerca do paciente e de suas preferências; quer isto dizer, o mandatário não deve indicar o que melhore lhe parece, senão o que crê que o paciente teria escolhido para essa circunstância particular" (MANZINI, Jorge Luis. Lasdirectivas antecipadas para tratamientos médicos. In: MARINO, Ignazio R. Testamento biológico: i diretti dei malati e l'operato dei Médici. In: BORASCHI, Andrea; MANCONI, Luigi. Il dolore e la política. Milão: Bruno Mondadori, 2007, p. 41.) 
artificialmente. Em grande medida, essas decisões são tomadas com base nas crenças religiosas das pessoas. Não parece equivocado, portanto, se admitir que o indivíduo indique uma pessoa para decidir por ele com base em disposições que podem não estar contidas num testamento vital. O que se deve avaliar é, tão somente, se existia uma relação de confiança entre as partes e se a procuração foi feita sem qualquer vício do consentimento, no pleno gozo das faculdades mentais do declarante. Agindo assim, o mandatário estaria respeitando os interesses do mandante.

Dessa maneira, permite-se respeitar a vontade do declarante que tem o direito de não decidir, ele mesmo, quais tratamentos deseja ou não seguir. Se ele opta por delegar essa decisão a uma outra pessoa, não há qualquer prejuízo, desde que sua vontade tenha sido manifestada de forma clara, inequívoca e livre de quaisquer vícios de consentimento.

Arremata José Alberto Gonzáles:

O procurador não é um simples núncio, porque, devendo embora levar em conta os valores vitais perfilhados pelo outorgante para fazer as opções que lhe cabem, goza de uma margem mais ou menos ampla de atuação. A largueza dos seus poderes variará, certamente, em função da vontade e das instruções que este atempadamente lhe houver dado, mas também em atenção ao padrão vital que ele tenha adotado ao longo da vida. Nesta medida (dependendo, é certo, da largueza dos poderes concedidos e das instruções conferidas), por poder representar um autêntico "cheque em branco", a procuração de cuidados de saúde mostra-se bem mais arriscada para o outorgante do que o testamento vital.43

Conclui-se, portanto, que, apesar de incomum, não há óbice a que haja somente uma procuração para cuidados de saúde, sem testamento vital, e que esta dê carta branca ao procurador para ele agir segundo a sua vontade e não segundo a vontade presumida do declarante, expressa num papel ${ }^{44}$. Afinal, se ele deposita sua confiança neste procurador, o que ele faz, na verdade, é declarar que sua vontade é que ele decida em seu lugar. E isso está albergado na autonomia existencial do declarante. Basta pensar que, se não fosse o procurador a decidir por ela, provavelmente a decisão caberia a alguém que ela não conhece ou pode não confiar, como, por exemplo, os médicos e os familiares.

Com efeito, ainda que se entenda que essa delegação desnature o instituto tal como ele foi concebido, a autonomia existencial do declarante parece tutelar esse novo arranjo de alguma forma.

\section{CONSIDERAÇÕES FINAIS}

43 GONZÁLES, José Alberto. Testamento Vital e Procuração de Cuidados de Saúde. Lisboa: Quid Juris, 2013, p. 140

44 José Alberto Gonzáles entende ser um dever do mandatário atuar no interesse do representado. Ver mais em: GONZÁLES, José Alberto. Testamento Vital e Procuração de Cuidados de Saúde. Lisboa: Quid Juris, 2013, p. 145 
O presente estudo buscou analisar, sobretudo através da formulação de hipóteses e do recurso comparativo a alguns ordenamentos estrangeiros, as principais questões atinentes à validade e à efetividade das Diretivas Antecipadas de Vontade no Brasil.

Partindo-se da distinção entre testamento vital e mandato duradouro, pretendeu-se investigar as soluções possíveis dentro do ordenamento jurídico brasileiro que, à exceção da Resolução nº. 1995/2012 do Conselho Federal de Medicina, não possui qualquer outro instrumento que discipline o tema das diretivas antecipadas de vontade.

Cabe ainda à doutrina e à jurisprudência delinear os contornos desse instituto, que precisa ser legislado o mais breve possível, dada a multiplicidade de questões que têm surgido de sua aplicação prática.

Assim, se apontou a necessidade da criação de um registro nacional de diretivas antecipadas como forma de conferir maior efetividade à implementação do conteúdo das diretivas, que, em muitos casos, acabam não sendo até mesmo conhecidas pelos médicos que cuidam do paciente em estado de terminalidade.

Desse modo, uma ideia positiva seria impor aos hospitais a obrigação de checagem desse registro, como forma de garantir que nenhuma diretiva seja descumprida pelo simples fato de que não foi levada ao conhecimento do corpo médico.

Questões como o prazo de validade e a revogabilidade deverão ser enfrentadas pelo legislador brasileiro. Quanto a esta última, não parece haver muitas dúvidas. Já quanto à primeira, será preciso avaliar qual o melhor modelo e, para isso, o recurso ao direito estrangeiro parece ser uma opção válida, pois muitos países já contam com legislações específicas sobre o tema, a exemplo de Portugal, onde o prazo de eficácia é de 5 anos, sendo renovado toda vez que uma modificação é aposta ao documento. ${ }^{45}$ Esta parece ser uma solução

\footnotetext{
45 Lei 25/2012, de 16 de Julho, Portugal

"Artigo 7."

Prazo de eficácia do documento

1 - O documento de diretivas antecipadas de vontade é eficaz por um prazo de cinco anos a contar da sua assinatura.

2 - O prazo referido no número anterior é sucessivamente renovável mediante declaração de confirmação do disposto no documento de diretivas antecipadas de vontade, de acordo com o disposto no n. ${ }^{\circ} 1$ do artigo $3 .^{\circ}$

3 - O documento de diretivas antecipadas de vontade mantém-se em vigor quando ocorra a incapacidade do outorgante no decurso do prazo referido no . $^{\circ} 1$.

4 - Os serviços de RENTEV devem informar por escrito o outorgante de DAV, e, caso exista, o seu procurador, da data de caducidade do documento, até 60 dias antes de concluído o prazo referido no n. ${ }^{\circ} 1$. Artigo $8 .^{\circ}$

Modificação ou revogação do documento

1 - O documento de diretivas antecipadas de vontade é revogável ou modificável, no todo ou em parte, em qualquer momento, pelo seu autor.
} 
interessante, embora imponha ao declarante a obrigação de ter que confirmar de cinco em cinco anos o conteúdo das suas diretivas. Outrossim, em Portugal elimina-se o risco de que isso caia no esquecimento, pois há uma obrigação de que os serviços de RENTEV informem por escrito o outorgante ou o procurador da caducidade do documento, até 60 dias antes de concluído o prazo da perda de eficácia.

Diante do exposto, pode-se concluir que há um oceano de perguntas e um riacho de respostas. Cabe à doutrina, entretanto, irrigar esse riacho, transformando-o em um rio navegável, pois não se pode pretender eliminar todas as dúvidas, mas, é papel da doutrina minorá-las. É preciso, pois, ter sempre em vista, que as diretivas manifestam a vontade da pessoa humana sobre o seu processo de uma morte digna, o que deve ser objeto crescente de estudo e de intervenção legislativa, a fim de garantir a dignidade que lhe é ínsita, pois através das diretivas, promove-se a liberdade e a autonomia existencial.

Retomando Gilberto Gil, as diretivas são importantes porque, diferentemente do testamento, quando já se morreu, no processo de morte ainda se está aqui. E ainda se pode sofrer. Cabe ao Direito ajudar a diminuir esse sofrimento.

\section{REFERENCIAS}

ASCENSÃO, José de Oliveira. As disposições antecipadas de vontade - o chamado "testamento vital". Rev. Fac. Direito UFMG, Belo Horizonte, n. 64, pp. 493-517, jan./jun. 2014

BANDEIRA, M. Diretivas antecipadas de vontade: muitas questões e ainda mais respostas. Faculdade de Medicina, Universidade de Coimbra, Portugal. Disponível em: <https://estudogeral.sib.uc.pt/bitstream/10316/37296/1/Diretivas\%20antecipadas\%20de\%20v ontade $\% 20$ muitas $\% 20$ questoes $\% 20 \mathrm{e} \% 20$ ainda\%20mais\%20respostas.pdf $>$ Acesso em 03 fev. 2019

BARROSO, Luís Roberto; MARTEL, Letícia de Campos Velho. A morte como ela é: dignidade e autonomia individual no final da vida. Os Constitucionalistas. Disponível em: <http://osconstitucionalistas.com.br/Artigos/A_Morte_Como_Ela_E-Barroso_Martel.pdf> Acesso em 03 fev. 2019

2 - Sem prejuízo do disposto no n. ${ }^{\circ}$, a modificação do documento de diretivas antecipadas de vontade está sujeita à forma prevista no artigo $3 .^{\circ}$

3 - O prazo de eficácia do documento de diretivas antecipadas de vontade é renovado sempre que nele seja introduzida uma modificação.

4 - O outorgante pode, a qualquer momento e através de simples declaração oral ao responsável pela prestação de cuidados de saúde, modificar ou revogar o seu documento de diretivas antecipadas de vontade, devendo esse facto ser inscrito no processo clínico, no RENTEV, quando aí esteja registado, e comunicado ao procurador de cuidados de saúde, quando exista."

(http://www.pgdlisboa.pt/leis/lei_mostra_articulado.php?nid=1765\&tabela=leis) 
BEAUCHAMP, Tom L.; CHILDRESS, James F. Princípios de ética biomédica. Tradução de Luciana Pudenzi. São Paulo: Loyola, 2002

DADALTO, Luciana. Aspectos registrais das diretivas antecipadas de vontade. Civilistica.com, a. 2. n. 4. 2013

DADALTO, Luciana. Reflexos jurídicos da Resolução CFM 1.995/12. Revbioét (Impr.) 2013; 21 (1): 106-12

DADALTO, Luciana. Testamento Vital, 3. ed. São Paulo: Atlas, 2015

DADALTO, Luciana; TUPINAMBÁS, Unai; GRECO, Direceu Bartolomeu. Diretivas antecipadas de vontade: um modelo brasileiro. Rev. bioét. (Impr.). 2013; 21 (3): 463-76

FARAH, Elias. Testamento vital. Instituto em discussão. Breves reflexões sobre o tema. Previsão Legislativa. Revista de Direito de Família e das Sucessões, vol. 7, 2016, Jan/Mar, 2016

GONZÁLES, José Alberto. Testamento Vital e Procuração de Cuidados de Saúde. Lisboa: Quid Juris, 2013

MANZINI, Jorge Luis. Lasdirectivas antecipadas para tratamientos médicos. In: MARINO, Ignazio R. Testamento biológico: i diretti dei malati e l'operato dei Médici. In: BORASCHI, Andrea; MANCONI, Luigi. Il dolore e la política. Milão: Bruno Mondadori, 2007

PONA, Éverton Willian. Testamento vital e autonomia privada. Curitiba: Juruá, 2015

REGISTRO NACIONAL DE TESTAMENTO VITAL - RENTEV: www.rentev.com.br

RODRIGUES JUNIOR, Otavio Luiz. Diretivas antecipadas de vontade: questões jurídicas sobre seu conceito, objeto, fundamento e formalização, pp. 381-392. In: SILVEIRA, Renato de Mello Jorge; GOMES, Mariângela Gama de Magalhães. (organizadores). Estudos em homenagem a IvetteSenise Ferreira. São Paulo: LiberArs, 2015

SÁ, Maria de Fátima Freire de; MOUREIRA, Diogo Luna. Autonomia para morrer: eutanásia, suicídio assistido, diretivas antecipadas de vontade e cuidados paliativos, 2 . ed. Belo Horizonte: Del Rey, 2015

SOUZA, Amanda Cordeiro de. Diretivas antecipadas de vontade: dignidade e autonomia. In: Revista de Direito de Família e das Sucessões (RDFAS), coord. Carlos Alberto Garbi, Regina Beatriz Tavares da Silva e Theodureto de Almeida Camargo Neto. São Paulo: Associação de Direito de Família e das Sucessões, jul/set. 2017, v. 13

TEPEDINO, Gustavo. Marchas e contramarchas da constitucionalização do Direito Civil: a interpretação do direito privado à luz da Constituição da República. [Syn]Thesis, Rio de Janeiro, vol.5, $\mathrm{n}^{\circ} 1,2012$ 